\title{
PRC skewness determines synchronization properties of pulse coupled circuits with delay
}

\author{
Shuoguo Wang ${ }^{1}$, Lakshmi Chandrasekaran ${ }^{1}$, Fernando Fernandez ${ }^{3}$, John White ${ }^{3}$, Carmen C Canavier ${ }^{1,2^{*}}$ \\ From Nineteenth Annual Computational Neuroscience Meeting: CNS*2010 \\ San Antonio, TX, USA. 24-30 July 2010
}

Long range synchrony occurs by locking to a common input or via reciprocal coupling [1]. It is an open question as to how stable synchronization properties of neural circuits are sustained over long distances. We analyze two reciprocally coupled oscillatory neurons with conduction delays. We use Phase Resetting Curves (PRCs) generated under the assumption of pulsatile coupling to predict what phase-locked solutions will be exhibited in the neuronal circuit with delays. We test our predictions in circuits of two model neurons as well as in hybrid circuits constructed with two entorhinal cortex stellate cells (or two pyramidal cells) coupled via the dynamic clamp. Both Type I and Type II PRCs exhibit a peak advance
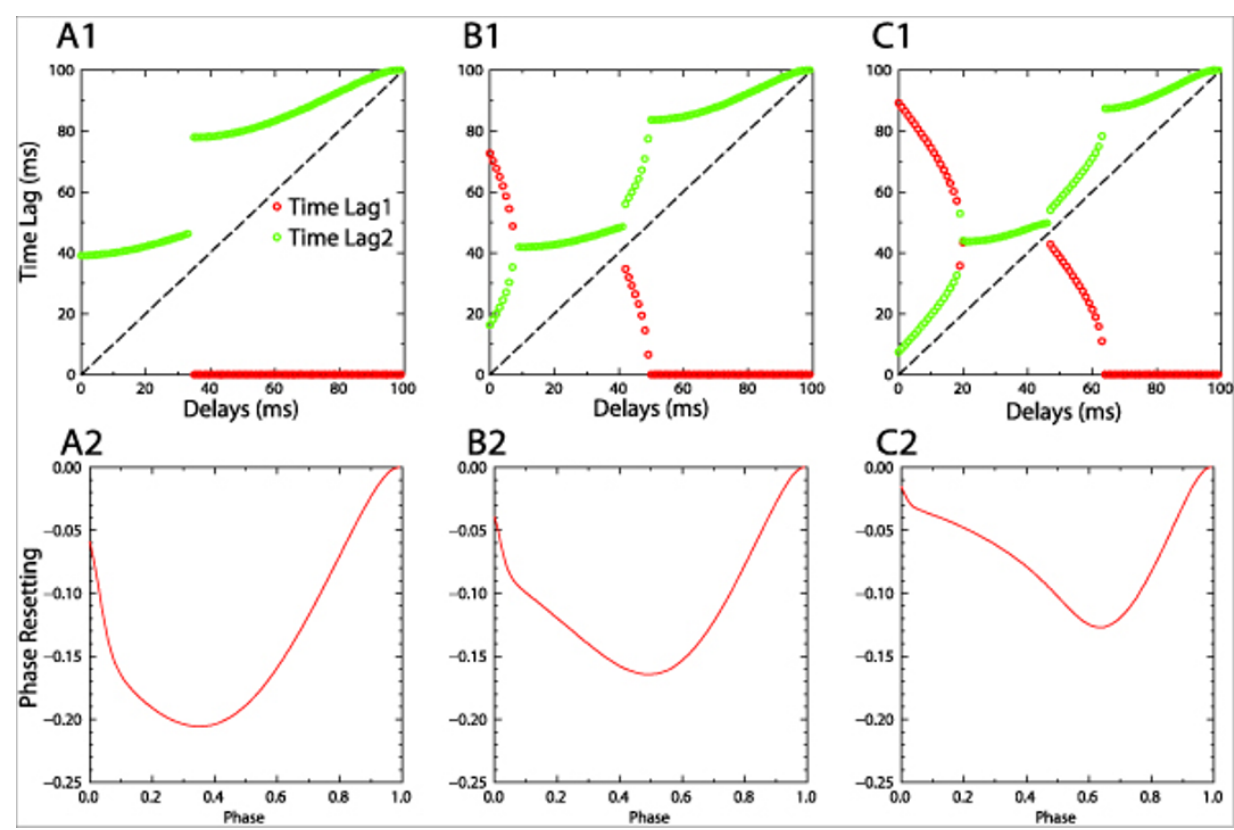

Figure 1 Right skewed PRC gives rise to leader-follower locking mode. A1, A2). Time lags indicate the time from spiking of one neuron to that of the other neuron and vice-versa. Only anti-phase and synchronous modes were observed with original Wang-Buzsaki (WB) model in which PRC is left skewed. B1, B2). Leader-follower mode is approached when original WB PRC is skewed toward the right. C1, C2). The leaderfollower mode is more closely approximated as the PRC is further right skewed. A negative value for resetting indicates an advance in our convention.

* Correspondence: ccanav@lsuhsc.edu

1 Neuroscience Center of Excellence, LSU Health Sciences Center, New Orleans, LA, 70112, USA 
in response to an excitation. If this peak is skew left by our convention (see Fig. 1A), then synchrony and anti-phase emerge as generic solutions for identical neurons, and persist approximately for nonidentical neurons. However, experimentally, a leader/follower solution was observed instead, in which one of the time lags between the firing of the two neurons is approximately equal to the delay. The peak of the advances in the biological neurons was skew right. The parameters of the model were adjusted to produce a right skew and a leader/follower solution emerged (see Fig 1C). The leader follower mode becomes generic as the PRC at late phases approached the causal limit in which an input immediately evokes a spike, with a continuum of solutions observed in between (Fig 1B). We theoretically derive conditions on the existence and stability of the leader/follower solution. Future work will focus on obtaining these conditions in terms of the skewness of the PRC.

\section{Acknowledgements}

This work was supported by the NIH grants NS54281 and MH85387 to C. C. Canavier.

\section{Author details}

${ }^{1}$ Neuroscience Center of Excellence, LSU Health Sciences Center, New Orleans, LA, 70112, USA. ²Department of Ophthalmology, LSU Health Sciences Center, New Orleans, LA, 70112, USA. ${ }^{3}$ Department of

Bioengineering, University of Utah, Salt Lake City, UT, 80305, USA.

Published: 20 July 2010

\section{Reference}

1. Tort ABL, Rotstein HG, Dugladze T, Gloveli T, Kopell NJ: On the formation of gamma-coherent cell assemblies by oriens lacunosum-moleculare interneurons in the hippocampus. Proc Natl Acad Sci U S A 2007, 104(33):13490-13495.

doi:10.1186/1471-2202-11-S1-P10

Cite this article as: Wang et al:: PRC skewness determines

synchronization properties of pulse coupled circuits with delay . BMC

Neuroscience 2010 11(Suppl 1):P10.

\section{Submit your next manuscript to BioMed Central} and take full advantage of:

- Convenient online submission

- Thorough peer review

- No space constraints or color figure charges

- Immediate publication on acceptance

- Inclusion in PubMed, CAS, Scopus and Google Scholar

- Research which is freely available for redistribution

Submit your manuscript at www.biomedcentral.com/submit 